Saudi Journal of Oral and Dental Research

Abbreviated Key Title: Saudi J Oral Dent Res

ISSN 2518-1300 (Print) |ISSN 2518-1297 (Online)

Scholars Middle East Publishers, Dubai, United Arab Emirates

Journal homepage: https://saudijournals.com

Review Article

\title{
Cissus Quadrangularis- Potential Dental Biomaterial
}

Dr. Poonam Shingare (M.D.S)

Associate Professor, Department of Pediatric and Preventive Dentistry, Government Dental College and Hospital, Aurangabad 431001, Maharashtra, India

DOI: 10.36348/sjodr.2021.v06i02.003 | | Received: 02.02.2021 | Accepted: 12.02.2021 | Published: 17.02 .2021

*Corresponding author: Dr. Poonam Shingare

\section{Abstract}

Indian system of medicines like Ayurveda, Siddha and Unani utilize large number of medicinal plants for the treatment of various illnesses of mankind. According to WHO $80 \%$ of world population depends upon traditional system of medicine. Cissus Quadrangularis is medicinal plant belonging to Family Vitaceae, is commonly known as Veldt Grape or Devil's Backbone. Popularly known as Hadjod (Bone setter) in Hindi. From ancient times it has been used as curative agent in various diseases particularly for bone healing, digestive aid and cure of piles. Considering its therapeutic value this review has been done to compile information of various researches done on this plant with emphasis on its potential applications in Dentistry.

Keywords: Hadjod, medicinal plants, Ayurvedic herb, bone healing, herbal formulations.

Copyright () 2021 The Author(s): This is an open-access article distributed under the terms of the Creative Commons Attribution 4.0 International License (CC BY-NC 4.0) which permits unrestricted use, distribution, and reproduction in any medium for non-commercial use provided the original author and source are credited.

\section{INTRODUCTION}

Various traditional therapies for treatment of physical and mental illnessess exist in all major ancient civilizations of the world. C.Q. plant extract is used in Indian subcontinent and is one of the most popular traditional therapies [1]. In today's scenario there has been an increasing focus of research on plants for their medicinal usefulness in different parts of the world. Cissus quadrangularis (Linn) is an indigenous medicinal plant seen in India which has been reported to be used in ayurvedic medicine for promotion of fracture healing process and well known as "Hadjod". The plant is a perennial climber which belongs to family Vitaceae and is distributed throughout India particularly in tropical regions. It is famous by different names in various vernacular languages. It is called as as Hadjod in Hindi, it is famous as Vajravalli, ashtishrunkhala in Sanskrit. It is known as Kandvel in Marathi, Haddjor in Punjabi, in Orisa it is called as Hadbhanga, known as Vedhari in Gujrati, Perandi in Tamil, Nalleru in Telagu, and Veldgrap, Edible Vine in English [2].
Table-1: The scientific nomenclature of Cissus Quadrangularis [2, 3]:

\begin{tabular}{|l|l|}
\hline Kingdom: & Plantae \\
\hline Subkingdom & Tracheobionta \\
\hline Division: & Magnoliophyta \\
\hline Superdivision & Spermatophyte \\
\hline Class: & Magnoliopsida \\
\hline Subclass & Rosidae \\
\hline Order & Vitales \\
\hline Family: & Vitaceae \\
\hline Genus: & Cissus \\
\hline Species: & Qundrangularis \\
\hline
\end{tabular}

Description of the plant-

The plant comprises simple or reniform, serrate wide leaf and four angled stem connected at nodes, internodes which are up to $10 \mathrm{~cm}$ long and dichotomously branched.

All parts of plant -stem, root, leaves, shoot and dried ash are used for medicinal purpose.

Therapeutic uses 
Poonam Shingare; Saudi J Oral Dent Res, Feb, 2021; 6(2): 97-101

The stem of the plant which is quadrangular in shape is used for the treatment of bone fractures mainly and also for gastritis, constipations, piles, anemia, skin infections, eye diseases, asthma, irregular menstruation, burns and wounds traditionally. The powder form of stem is used for the treatment of hemorrhoids and certain bowl infections. The juice preparation made from the stem is used for treatment of scurvy and irregular menstruation, the paste made from stem is boiled with lime water and used to treat asthma [2].

\section{Therapeutic properties}

The plant is reported have various therapeutic properties the most important one is bone fracture healing property. Other properties cited in literature are antimicrobial, antifungal, antiulcer, antioxidative, antihelminthic, antihemorrhoidal, antiosteoporotic, gastroprotective, analgesic, anticancer [3], cholinergic activity as well as beneficial effects on cardiovascular diseases [2, 4]. The widespread therapeutic properties are related to various pharmacological actions.

\section{Phytochemistry}

Phytochemical analysis of Cissus qudrangularis have been researched by various authors and showed to contain various constituents such as flavinoids, triterpenoids, vitamin $\mathrm{C}$, carotene $\mathrm{A}$, anabolic steroidal substances, calcium, stilbene derivatives and many others e.g resveratrol, piceatannol, pallidol perthenocissin and phytosterols.

According to Garima et al. ascorbic acid, $\beta$ sitosterol, triterpene, calcium, ketosteroid, and two asymmetrical tetracyclic triterpenoids were identified as major constituents of this plant $[2,4]$.

\section{Pharmacological activity}

\section{Bone fracture healing activity}

- Cissus quadrangularis is commonly known as the "bone setter". Various researches to study the effect of C.Q on healing of fractures shown that an anabolic steroid present in C.Q act as estrogenic receptors of bone which cause early ossification and increase uptake of Calcium, Sulpher and strontium by osteoblasts. During healing of fracture there is early regeneration of all connective tissue and rapid mineralization of callus under the influence of vitamins and steroids present in C.Q [2]

C.Q cause stimulation of all cells of mesenchymal origin namely the fibroblasts, the chondroblasts and osteoblasts with more impact on osteoblastic proliferation. This activity leads to shortening of bone healing period by 2 weeks.

Adult dog studies showed increase in alkaline phosphatase level during fracture healing. Other studies reported that C.Q causes rapid accumulation of larger quantity of mucopolysaccharides during first week which is followed by rapid fall and cause early disappearance of them from the fractured area. Both these actions benefit healing of fractures.

C.Q acts by up regulating MAPK dependant alkaline phosphatase activity in osteoblasts which leads to increase biomineralization [5]. There is increased DNA synthesis, increased matrix mineralization of human osteoblast like SaOS-2 cells. C.Q exerts anabolic action in human osteoblast like cells through increased mRNA and protein expression of Runx 2 which is involved in regulation of bone matrix proteins [6]. RT PCR studies showed that there is increasing in mRNA expression of IGF I, II and IGF BP-3 [7]. Vitamin $\mathrm{C}$ and $\mathrm{A}$ found in C.Q helps in formation of collagen. Steroids such as Cortisone have antianabolic effect which inhibits tissue regeneration and repair and retards formation of specific skeletal. C.Q counteracts these antianabolic effects of cortisone in the healing of fractures. Under the influence of C.Q it has been reported that there is minimum tissue reaction with optimum decalcification and minimum callus formation which helps in deposition of calcium which is just sufficient to join the two fractured segments so remodeling happens in less time and also fractured segments gain tensile strength early [8].

Antiosteoporotic activity

- Osteoporosis is a silent disease. It is a chronic, progressive condition associated with microarchitectural deterioration of bone tissue results in low bone mass. In cases of postmenopausal osteoporosis C.Q acts by counteracting the antianabolic effects and this action helps to recover the bone mineral density [2]. Because of its property of stimulation of osteoblastogenesis, C.Q is used as preventive/ alternative natural medicine for bone diseases such as osteoporosis [9].

Antioxidant activity

- EECQ and MECQ showed potent antioxidant effect and also showed pronounced anticancer efficacy against leukemic cells HL-60 [10]. Various biological and photochemical reactions in body generate superoxide radical $\mathrm{O}_{2}{ }^{-}$, which is a highly toxic. C.Q has scavenging effect because of its hydrogen donating ability [11]. $\beta$-carotene present in C.Q [13] scavenges superoxide radical and suppresses singlet oxygen. Nair et al. [14] have suggested that vitamin $\mathrm{C}$, the major constituent of C.Q has in vitro lipid peroxidation inhibition capability and scavenging action on peroxyl and hydroxyl radicals. The free radical scavenging and 
antioxidant activity is attributed to the antioxidative composition of C.Q [15].

Anabolic and androgenic activity

- Cortisol and Endogenous glucocorticoids activate pathways to cause degradation of bone and skeletal as well as muscle tissue. Glucocorticoids induce muscle breakdown. The activation of the Ubiquitin-Proteasome pathway of proteolysis by glucocorticoid cause tissue breakdown which is helpful in removing damaged and nonfunctional proteins. C.Q has anabolic antiglucocorticoid effect and help to preserve muscle tissue during times of physical and emotional stress, which is useful property for average bodybuilder or athelete $[2,16]$.

Anti-inflammatory activity

- C.Q contains bioflavonoids, numerous flavanoids, several flavones, flavonols, flavanols and flavanoids especially luteolin. All of these act by inhibiting the lipooxygenase pathway. $\beta$ sitosterol also called plant cholesterol also have anti-inflammatory activity. C.Q acts on both the cyclooxygenase and lipoxygenase pathways of arachidonic acid metabolism and cause inhibition. Therefore C.Q acts as dual inhibitor of arachidonic acid metabolism [2, 17].

Antihemorrhoidal activity

- C.Q is used for the treatment of hemorrhoids and varicose veins. The bioflavonoids mainly diosmin, hesperidine and oligomeric proanthocyanidin reported to have phlebotonic activity, vasculoprotective effects and antagonistic effect on the biochemical mediators of inflammation $[2,17]$.

Gastroprotective and Antiulcer activity

- C.Q has gastroprotective effect mainly by improving muscle resistance against ulcerogens and promoting cellular proliferation to cause healing. It is effective in treatment of peptic ulcer disease also.

Metabolic syndrome and weight loss

- The phytosterols and fiber extracts present in C.Q have anti lipase and anorexiant properties which cause less absorption of dietary fats and increases satiation by causing rise in serum serotonin levels [18]. Owing to this property C.Q is been effectively used for the management of weight loss and metabolic syndrome mainly for central obesity.

Safety and efficacy

- Critical appraisal of clinical effects of C.Q was done by Sawangjit et al. They explored 12 electronic databases to include publications and included total 9 studies with 1108 patients. Effects of cissus combination products on body weight reduction low density lipoprotein, triglyceride, total cholesterol and fasting blood sugar were superior to placebo [19].

- Animal and in vitro studies provide support for the use of cissus in promoting bone fracture healing and as an antiosteoporotic. Human studies support the use of cissus extracts in weight management. No studies have been demonstrating it's anabolic and body building activities [20].

\section{Applications in Dentistry Dental caries [21]}

Dental caries is a result of acid demeralizatioin of enamel or dentin which is induced by plaque (biofilm) and mediated by saliva [22]. The dental biofilm composition show multifarious microbial community. Streptococcus mutans and lactobacillus acidophilus present in biofilm play a key role in the initiation and progression of caries. Cissus quadrangularis was found to have versatile antibacterial activity against different microorganism. Kesavraj et al. investigated the antibacterial effects of cissus quadrangularis and compared with calcium hydroxide against s. mutans and L.acidophilus and confirmed the antibacterial potential of C.Q against cariogenic microorganisms.

\section{Periodontal regenerative therapy}

The role of C.Q in PDL regeneration of intrabony periodontal defects has been evaluated in association with hydroxyapatite bone filler [23]. The C.Q with H.A showed slight better performance but without much statistical significance.

\section{Implant dentistry}

One of the challenges in implant placement is always to make the time shorter for bone healing post dental implant placement. Hydrophilic dental implant surface is a new topic of interest to stimulate osseointegration. The study by Roy et al showed that C.Q and Chitosan hydrogel coated implants can reach firm stability in bone and may offer promising results promoting early loading of implants [24].

Various modifications of conventional implant surface are under the process of development mainly to promote an increased and faster bone to implant contact.

Ranka et al. prepared C.Q, HA and Chitosan composite polyelectrolyte solution for surface treatment of titanium implants and demonstrated that this polyelectrolyte scaffold was biomimetic, angiogenic and antimicrobial with considerable potential for cellular adhesion, proliferation and differentiation [25]. 
Poonam Shingare; Saudi J Oral Dent Res, Feb, 2021; 6(2): 97-101

\section{Synthesis of hydroxyapatite}

The Cissus quadrangularis plant is composed high percentage of calcium mainly in its thick cell wall, which makes it suitable for growth of mineral crystals and the phosphorous content of the plant can also be explored for synthesizing hydroxyapatite, thus utilizing the traditional knowledge of bone fracture healing in advanced technique of new material synthesis. It was shown that calcite crystals were formed by simply bubbling $\mathrm{CO}_{2}$ into aqueous C.Q extract [1].

\section{CONCLUSION}

Plant based natural products as medicine has higher demand at present. C.Q exhibits required therapeutic properties in both traditional and allopathic medicine. C.Q treatment of implant surfaces opens a new avenue for research in implant tissue engineering. It can also be researched for synthesis of hydroxyapatite. Owing of its osteogenic potential and antimicrobial properties it can have promising future as pulp capping agent, in apexogenesis procedures.

Its role as anticariogenic agent, as a pulp capping agent and for apexogenesis procedures needs to be explored with more in vitro and in vivo studies. It is a valuable medicinal plant that could benefit dental research field greatly.

\section{Abbreviations}

C.Q- Cissus Qudrangularis

MAPK- Mitogen activated protein kinase

Runx2- Runt related transcription factor 2

EECQ-ethanolic extract of cissus qudrangularis

MECQ-methanolic extract of cissus qudrangularis

DNA-deoxyribo nucleic acid

mRNA- messenger ribonucleic acid

HA-hydroxyapatite

\section{REFERENCES}

1. Sanyal, A., Ahmad, A., \& Sastry, M. (2005). Calcite growth in Cissus quadrangularis plant extract, a traditional Indian bone-healing aid. Current science, 1742-1745.

2. Mishra, G., Srivastava, S., \& Nagori, B. P. (2010). Pharmacological and therapeutic activity of Cissus quadrangularis: an overview. International journal of pharmtech research, 2(2), 1298-1310.

3. Camil, R.M., Lokesh, R. (2020). A review of Cissus quadrangularis L. as herbal Medicine. Indian J Nat Prod Rsour, 11(30:155-164.

4. Managutti, A., Shah, D., Patel, J., Puttanikar, N., Shah, D., \& Managutti, S. (2015). Evaluation of clinical efficacy of cissus quadrangularis in pain management and bone healing after implant placement-a pilot study. Medico Research Chronicles, 2(5), 618-625.

5. Parisuthiman, D., Singhatanadgit, W., Dechatiwongse, T., \& Koontongkaew, S. (2009). Cissus quadrangularis extract enhances biomineralization through up-regulation of MAPKdependent alkaline phosphatase activity in osteoblasts. In Vitro Cellular \& Developmental Biology-Animal, 45(3-4), 194-200.

6. Muthusami, S., Senthilkumar, K., Vignesh, C., Ilangovan, R., Stanley, J., Selvamurugan, N., \& Srinivasan, N. (2011). Effects of Cissus quadrangularis on the proliferation, differentiation and matrix mineralization of human osteoblast like SaOS2 cells. Journal of Cellular Biochemistry, 112(4), 1035-1045.

7. Muthusami, S., Ramachandran, I., Krishnamoorthy, S., Govindan, R., \& Narasimhan, S. (2011). Cissus quadrangularis augments IGF system components in human osteoblast like SaOS-2 cells. Growth Hormone \& IGF Research, 21(6), 343-348.

8. Brahmkshatriya, H. R., Shah, K. A., Ananthkumar, G. B., \& Brahmkshatriya, M. H. (2015). Clinical evaluation of Cissus quadrangularis as osteogenic agent in maxillofacial fracture: A pilot study. Ayu, 36(2), 169.

9. Potu, B. K., Bhat, K. M., Rao, M. S., Nampurath, G. K., Chamallamudi, M. R., Nayak, S. R., \& Muttigi, M. S. (2009). Petroleum ether extract of Cissus quadrangularis (Linn.) enhances bone marrow mesenchymal stem cell proliferation and facilitates osteoblastogenesis. Clinics, 64(10), $993-$ 998.

10. Dhanasekaran, S. (2020). Phytochemical characteristics of aerial part of Cissus quadrangularis (L) and its in-vitro inhibitory activity against leukemic cells and antioxidant properties. Saudi journal of biological sciences, 27(5), 1302-1309.

11. Shimada, K., Fujikawa, K., Yhara, K., Nakamura, T. (1992). Antioxidative properties of xanthone on the auto oxidation of soybean in cyclodextrin emulsion. J Agric Food Chem, 40(6):945-948.

12. Govindarajan, R., Vijayakumar, M., Rawat, A. K. S., \& Mehrotra, S. (2003). Free radical scavenging potential of Picrorhiza kurrooa Royle ex Benth.

13. Chidambara Murthy, K. N., Vanitha, A., Mahadeva Swamy, M., \& Ravishankar, G. A. (2003). Antioxidant and antimicrobial activity of Cissus quadrangularis L. Journal of medicinal food, 6(2), 99-105.

14. Nair, S., Norkus, E. P., Hertan, H., \& Pitchumoni, C. S. (2000). Micronutrient antioxidants in gastric mucosa and serum in patients with gastritis and gastric ulcer: does Helicobacter pylori infection affect the mucosal levels?. Journal of clinical gastroenterology, 30(4), 381-385.

15. Jainu, M., \& Devi, C. S. (2005). In Vitro. and In Vivo. Evaluation of Free-Radical Scavenging Potential of Cissus quadrangularis. Pharmaceutical biology, 43(9), 773-779.

16. Ferrandiz, M. L., \& Alcaraz, M. J. (1991). Antiinflammatory activity and inhibition of arachidonic acid metabolism by flavonoids. Agents and actions, 32(3), 283-288. 
17. Panthong, A., Supraditaporn, W., Kanjanapothi, D., Taesotikul, T., \& Reutrakul, V. (2007). Analgesic, anti-inflammatory and venotonic effects of Cissus quadrangularis

Linn. Journal

of ethnopharmacology, 110(2), 264-270.

18. Oben, J., Kuate, D., Agbor, G., Momo, C., \& Talla, $X$. (2006). The use of a Cissus quadrangularis formulation in the management of weight loss and metabolic syndrome. Lipids in Health and Disease, 5(1), 1-7.

19. Sawangjit, R., Puttarak, P., Saokaew, S., \& Chaiyakunapruk, N. (2017). Efficacy and safety of Cissus Quadrangularis L. in clinical use: A systematic review and meta-analysis of randomized controlled trials. Phytotherapy Research, 31(4), 555-567.

20. Stohs, S. J., \& Ray, S. D. (2013). A review and evaluation of the efficacy and safety of Cissus quadrangularis research, 27(8), 1107-1114.

21. Kesavaraj, B., Asokan, S., GeethaPriya, P. R., Vijayasankari, V., \& Rubavathi, S. (2019). Antibacterial effect of Cissus quadrangularis against cariogenic microorganisms: An in vitro study. SRM Journal of Research in Dental Sciences, 10(2), 57.

22. American Academy of Pediatric Dentistry. (2005). American Academy of Pediatrics, American Academy of Pediatric Dentistry Council on Clinical Affairs. Policy on early childhood caries (ECC): Classification, consequences and preventive strategies. Pediatr Dent, 27:31-3

23. Varoni, E. M., Iriti, M., \& Rimondini, L. (2012). Plant products for innovative biomaterials in dentistry. Coatings, 2(3), 179-194.

24. Richa Roy, T., Nelogi, S., \& Ramesh, C. (2020). Evaluation of hydrophilic hydrogel prepared using Cissus quadrangularis in enhancing osseointegration of dental implants- a preliminary research in rabbits. Clinical Oral Implants Research, 31, 111-111.

25. Ritwik Ranka, R., Nelogi, S. Y., \& Ambi Nelogi, M. (2018). An in vitro analysis of surface characterization of titanium discs with novel polyelectrolytic hydrogel for implants tissue engineering. Clinical Oral Implants Research, 29, 232-232. 